\title{
Evaluation of Articulation of Turkish Phonemes after Removable Partial Denture Application
}

\author{
Murat ÖZBEK ${ }^{1}$ \\ abrahim TULUNO־LU ${ }^{2}$ \\ Soner ÖZKAN ${ }^{3}$ \\ Müjgan ÖKTEMER ${ }^{2}$ \\ ${ }^{1}$ Department of Oral Diagnosis and Radiology, Faculty of Dentistry \\ ${ }^{2}$ Department of Prosthodontics, Faculty of Dentistry \\ ${ }^{3}$ Department of Otorhinolaryngology, Audiology and Speech Disorders, Faculty of Medicine \\ University of Hacettepe, Ankara, Turkey
}

\begin{abstract}
In this study, the adaptation of patients to removable partial dentures was evaluated related to articulation of Turkish phonemes. Articulation of /t,d,n,l,r/,/g,k/, /b,p,m/ and /s, z, Õ,v,f,y,j,h,c/ phonemes were evaluated by three speech pathologists, on records taken from 15 patients before the insertion of a removable partial denture, just after insertion, and one week later. The test consisted of evaluation of phoneme articulation of independent syllables in terms of distortion, omission, substitution, mass effect, hypernasality and hyponasality. Data were evaluated with Cochrane Q, McNemar and Kruskal-Wallis tests. The results showed that for some phonemes, problems in articulation occurred after the insertion of a removable partial denture while for others a significant amelioration was observed after the insertion of a removable partial denture. In general, problems in articulation of evaluated phonemes were resolved after one week of use.
\end{abstract}

Key Words: articulation, Turkish phonemes, removable partial denture.

\section{INTRODUCTION}

Phonation is one of the most important factors in daily life because of its direct and indirect effects on self and other activities. It becomes a whole with respiration, vocalization resonance, articulation and neurological integration (1). Phonation, which can be affected by various means, is a major function that enables a person to communicate vocally, express feelings, thoughts and emotions and become a social being. Articulation, a major element of this function, can be explained as formation of phonemes, a basic element of language. Articulators, such as tongue, palate, teeth, lips, cheek, alveoli and the lower jaw, function to form phonemes. Some phonemes become vowels as the vocal cords vibrate but a majority of these phonemes remain consonant, as no vibration is necessary. Air coming from the larynx is directed to two separate parts by velum.
Phonemes can be classified as linguo-palatal, linguo-alveolar, linguo-dental, linguo-velar, labio-dental, bilabial or glottal according to their place of formation (1-3). The vocalization process is reported $(2,3)$ to be formed by the harmonious and accurate cooperation of neurotransmissions in addition to 1) the motor organ that consists of lungs dealing with the air circulation and other respiratory muscles; 2) the vibrator organ, namely corda vocalis, forming vocalization; 3 ) resonator system, which creates the personal characteristics, formed by oral, nasal, pharyngeal cavities and paranasal sinuses; 4) articulators, formed by lips, tongue, soft palate, hard palate and teeth; 5) vocal area of the brain and motor vocal organs. According to Kent and Schaaf (2), articulation is affected mostly by dental defects compared to five main components of speech (respiration, phonation, resonation, articulation and neurological integration)

The close relation between phonemes and their

Correspondence: Doç. Dr. abrahim Tuluno ${ }^{\mathrm{TM}} \mathrm{lu}$, Department of Prosthodontics, Faculty of Dentistry, University of Hacettepe, 06100 Sihhiye, Ankara, Turkey. Tel: +90-312-324-6145. Fax: +90-312-311-3741. e-mail: itulunoglu@yahoo.com 
formation areas causes them to be affected by slight changes occurring at these sites. The most important and most frequent one of these relations is the partial or total loss or dislocation of teeth, that will affect not only the articulation of the phonemes, but also there would be changes in resonance because of the changes in the oral cavity structure.

In partial or total edentulousness, speech would be affected naturally as the phonemic articulation is affected. The teeth are known to have a specific role in the formation of certain phonemes (4). A prosthesis must be sufficiently satisfactory for aesthetics and masticatory activity as well as phonation and especially articulation. Thus, the location of the teeth on the denture should be accurate in order to allow the tongue and other articulators to work accurately.

After the insertion of a prosthesis, phonation, articulation, as well as resonance in the oral cavity, could change. Deficiency at the articulator formation, inappropriate location and dysfunction could lead to disarticulation of phonemes.

The most frequent articulation defects can be classified as omission, substitution, distortion, addition, and nasality and lisping (4). Omission is the absence of a phoneme in a word, substitution is the formation of a new phoneme by replacing a necessary phoneme by another in a word, and distortion is the inappropriate substitution of a phoneme that nearly fits. Addition is to add another phoneme next to the pronounced phoneme. The variations in resonance occur as hyper- or hyponasality. As a result of negative affection of velo-pharyngeal closure that separates the oral and nasal cavities at phonemic articulation, the air passage through the nasal cavity and consequently nasality at phonation increases. Also, the variations in tongue-palatal gutter and vertical dimension of occlusion may lead to lisping.

Therefore, in the adaptation period, a series of speech defects may be noted. As the patient uses his custom-made prosthesis with accurate biomechanical and physiological properties, these complaints decrease and elimination of these problems can be noted over time.

The close relations of phonemic parameters with intraoral structures clearly indicates the importance of prosthetic rehabilitation and the necessity of a prosthesis that corrects the phonemic articulation properties in addition to aesthetic and masticatory functions (3).
It has been shown that, even though the majority of phonemes appear to be common in almost all languages, their articulation areas can differ from one language to another $(5,6)$. In the Turkish language, the /O/ phoneme is comparable with the /sh/ phoneme in English and the /ch/ phoneme in French. It must also be noted that many linguo-alveolar phonemes in English such as /t,d,n,r/ are articulated more linguo-dentally in the Turkish language.

The purpose of this study was to evaluate the variations in articulation of Turkish phonemes in patients in whom removable partial dentures were applied, before insertion, just after insertion and one week later.

\section{MATERIAL AND METHODS}

A total number of 15 patients, who were seen at the Department of Prosthodontics, Faculty of Dentistry, Hacettepe University for prosthetic rehabilitation participated in this study. Informed consent was given. The patient population was demographically equilibrated consisting of 8 male and 7 female patients (35-45 years of age). Speech was recorded with a microphone held $20 \mathrm{~cm}$ away from patient's lips and the test consisted of meaningless syllable text formed by combinations of all consonant phonemes with all vowel phonemes used at the beginning, middle and end of the syllables. The phonemes evaluated with this test can be categorized into 4 groups: tip-tongue phonemes $/ \mathrm{t}, \mathrm{d}, \mathrm{n}, \mathrm{l}, \mathrm{r} /$; rear-tongue phonemes $/ \mathrm{g}, \mathrm{k} /$; bilabial phonemes $/ \mathrm{b}, \mathrm{p}, \mathrm{m} /$; fricative and other phonemes $/ \mathrm{s}, \mathrm{z}, \tilde{\mathrm{O}}, \mathrm{f}$, $\mathrm{y}, \mathrm{j}, \mathrm{h}, \mathrm{v}, \mathrm{c} / \mathrm{.}$

The tests were performed and recorded at three different times for each patient: before the insertion of the prosthesis, just after the insertion, and 7days after the insertion. Three speech pathologists evaluated all recordings blindly, in terms of distortion, omission, substitution, nasality and mass effect criteria with a $1 / 0$ scale. The data were evaluated statistically with Cochrane Q, McNemar and Kruskal-Wallis one-way ANOVA tests.

\section{RESULTS (Tables 1 and 2)}

Tip of tongue phonemes (anterior lingual phonemes). For $/ \mathrm{r} /$, excluding the relations between the second and third readings, there was a graded decrease 
in the disarticulation starting from the first reading to the second reading at the tip of tongue phonemes. When distortion is considered, the differences between the groups /t1-2/, /d1-3/, /n1-3/, /1 1-3/, /1 2-3/,/r1-2/, $/ \mathrm{r} 1-3 /$ were found to be statistically significant. In terms of omission, there was a decrease from the first through the second reading but only the differences between /r1-3/ values were statistically significant. The differences between the substitution values of / 11-3/, / 12-3/, $/ \mathrm{r} 1-3 /, / \mathrm{r} 2-3 /$ were found to be significant. The differences between the hypernasality values of /t1-2/, /t1-3/, /d1-2/,/n1-3/,/n1-2/,/11-2/, and /r1-2/ were found to be statistically significant. No significant differences were detected between the hyponasality values of the groups. When mass effect was considered, the variations between the groups /t2-3/,/d2-3/,/n2-3/,/12-3/,/r2-3/,/t12/,/d1-2/,/n1-2/,/11-2/,/r1-2/ were found to be statistically significant. In all groups, the mass effect values were increased from the first through the second readings but these values decreased from the second through the third readings.

Rear tongue phonemes $/ k, g /$. When distortion was considered, the differences between /g1-2/ groups were found to be significant. No significant differences were detected between the omission values of the groups. The differences between the substitution values of $/ \mathrm{k} 1$ $2 /$ and /k2-3/ groups were found to be statistically significant. When hypernasality was evaluated, the differences between the /k1-2/,/k1-3/ and /g1-2/, /g1-3/ groups were found to be significant. No significant differences were found between the hyponasality values of the groups. The differences between the mass effect values of /k1-2/, /k2-3/ and /g1-2/,/g2-3/ groups were found to be significant. In all groups, the mass effect values were increased from the first through the second readings but these values decreased from the second through the third readings.

Bilabial phonemes $/ b, p, m /$. When distortion was concerned, the differences between groups /b1-2/, /b2$3 /, / \mathrm{p} 1-2 /, / \mathrm{p} 1-3 /$ were found to be significant. There were no significant differences between omission values of $/ \mathrm{b}, \mathrm{p}, \mathrm{m} /$ groups. The differences between substitution values of /p1-3/ groups were significant. The differences between hypernasality values of $/ \mathrm{b} 1-2 /$, /b1-3/, /p1-2/, /p1-3/,/m1-2/ and /m1-3/ groups were significant. No significant differences were detected between hyponasality values of $/ \mathrm{b}, \mathrm{p}, \mathrm{m} /$ groups. When mass effect is considered, the differences between /b1- 2/,/b1-3/,/p1-2/,/p1-3/,/m1-2/ and /m1-3/ groups were found to be significant. In all groups, the mass effect values were increased from the first through the second readings but these values decreased from the second through the third readings.

Fricative and other phonemes. The differences between distortion values of /Õ1-3/, /f1-2/,/v1-3/, /ç1-3/, and /j1-3/ groups groups were significant. The differences between omission values of /s1-3/, /z1-3/, /f1-3/, /ç1-3/, and /j1-3/ groups were significant. The differences between substitution values of /1-2/, /2-3/ and /1$3 /$ subgroups of all phoneme groups were significant. The differences between hyper nasality values of /1-2/ and /1-3/ subgroups of all phoneme groups were significant. No significant differences were detected between hyponasality values of /s,z, Õ,f,v,ç,c,j,h,y/groups. The differences between mass effect values of $/ 1-2 /$ and /2-3/ subgroups of all phoneme groups were significant. In all groups, the mass effect values were increased from the first through the second readings but these values decreased from the second through the third readings.

\section{DISCUSSION}

Phonation problems and their treatment methods imply the necessity of teamwork. In evaluating the success of a prosthetic rehabilitation, phonetics is one of the major concerns because it is a basic human activity (3). The dimensions, locations and fabrication materials of the teeth as well as plaques affect speech and the voice. Articulation is formed as a result of the functional relations of various formations including the voice organ. The second important component controls the spreading of the sound waves by acoustic speech. Finally, the structure of the transformation of these sound waves into neurological impulses at the hearing organ and the interpretation of this message at cerebral levels forms the speech auditory components (7).

In this study, the auditory and acoustic components of these three important components are standardized, examining the adaptation period and the reaction of the patient to newly applied removable partial dentures. In order to standardize these components, tests were applied to every patient under the same conditions, with the same recording device and the same clinician.

Various methods were used to examine the struc- 
ture of the speech. These can be listed as listening to the direct sound, listening to recorded sound, spectrum analysis and use of a sound spectrogram in order to examine the diffusion of speech waves, evaluating the articulation with cephalographic film video fluoroscopy and palatography to determine the functional relations of oral tissues $(1,3,8-10)$. Although the evaluation of the tongue movement inside the mouth poses technical difficulties, computerized imaging methods, paleographic, radiological and acoustical methods currently provide important assistance in addition to the clinical evaluations $(7,10-12)$. The weak and subjective point of direct listening or recorded listening methods is the evaluators' perfection. However, in many other methods the examination of only one component of speech is possible and therefore differences resulting from personal characteristics of test subjects can sig- nificantly influence the reliability of the results. Thus, the reliability of the results in this study was provided by examining a wide range of phonemes used in the Turkish language and supported by the evaluation of the records by three speech pathologists, who were blinded.

Research has shown that prosthetic applications may cause quite a number of articulation defects (13), especially when the prosthesis is compensating the absence of teeth in the maxillary anterior region leading to problems in articulation of tip of tongue phonemes. Articulation is affected from the adaptation process to the increased vertical dimension of the prosthesis (14). In a similar study (9) in which possible articulation variations were evaluated, the /s,1,r,d,th,sh,k,f,t/ phonemes were evaluated at the first, third and sixth days after the insertion of a maxillary occlusal splint. The

Table 1. Cochrane Q test for detecting the differences between recording sequences of each criteria for each phoneme.

\begin{tabular}{|c|c|c|c|c|c|c|c|}
\hline Phonemes tested & Distortion & Omission & Subtraction & Hypernasality & Hyponasality & Flow & Mass effect \\
\hline \multicolumn{8}{|l|}{ Anterior lingual } \\
\hline$/ \mathrm{t} /$ & NS & NS & NS & $\mathrm{P}<0.05$ & NS & $\mathrm{P}<0.05$ & $\mathrm{P}<0.05$ \\
\hline$/ \mathrm{d} /$ & NS & $\mathrm{P}<0.05$ & NS & $\mathrm{P}<0.05$ & NS & $\mathrm{P}<0.05$ & $\mathrm{P}<0.05$ \\
\hline$/ \mathrm{n} /$ & $\mathrm{P}<0.05$ & NS & NS & $\mathrm{P}<0.05$ & NS & $\mathrm{P}<0.05$ & $\mathrm{P}<0.05$ \\
\hline$/ 1 /$ & $\mathrm{P}<0.05$ & NS & NS & $\mathrm{P}<0.05$ & NS & $\mathrm{P}<0.05$ & $\mathrm{P}<0.05$ \\
\hline$/ \mathrm{r} /$ & $\mathrm{P}<0.05$ & $\mathrm{P}<0.05$ & $\mathrm{P}<0.05$ & $\mathrm{P}<0.05$ & NS & $\mathrm{P}<0.05$ & $\mathrm{P}<0.05$ \\
\hline \multicolumn{8}{|l|}{ Posterior lingual } \\
\hline$/ \mathrm{k} /$ & NS & NS & NS & $\mathrm{P}<0.05$ & NS & $\mathrm{P}<0.05$ & $\mathrm{P}<0.05$ \\
\hline /g/ & NS & NS & NS & $\mathrm{P}<0.05$ & NS & $\mathrm{P}<0.05$ & $\mathrm{P}<0.05$ \\
\hline \multicolumn{8}{|l|}{ Bilabial } \\
\hline$/ \mathrm{b} /$ & NS & NS & NS & $\mathrm{P}<0.05$ & NS & $\mathrm{P}<0.05$ & $\mathrm{P}<0.05$ \\
\hline$/ \mathrm{p} /$ & NS & NS & NS & $\mathrm{P}<0.05$ & NS & $\mathrm{P}<0.05$ & $\mathrm{P}<0.05$ \\
\hline$/ \mathrm{m} /$ & NS & $\mathrm{P}<0.05$ & NS & $\mathrm{P}<0.05$ & NS & $\mathrm{P}<0.05$ & $\mathrm{P}<0.05$ \\
\hline \multicolumn{8}{|c|}{ Fricative and others } \\
\hline$/ \mathrm{s} /$ & NS & $\mathrm{P}<0.05$ & NS & $\mathrm{P}<0.05$ & NS & $\mathrm{P}<0.05$ & $\mathrm{P}<0.05$ \\
\hline$|z|$ & NS & $\mathrm{P}<0.05$ & NS & $\mathrm{P}<0.05$ & NS & $\mathrm{P}<0.05$ & $\mathrm{P}<0.05$ \\
\hline$\tilde{O}$ & $\mathrm{P}<0.05$ & NS & $\mathrm{P}<0.05$ & $\mathrm{P}<0.05$ & NS & $\mathrm{P}<0.05$ & $\mathrm{P}<0.05$ \\
\hline$/ \mathrm{f} /$ & $\mathrm{P}<0.05$ & $\mathrm{P}<0.05$ & $\mathrm{P}<0.05$ & $\mathrm{P}<0.05$ & NS & $\mathrm{P}<0.05$ & $\mathrm{P}<0.05$ \\
\hline$/ \mathrm{v} /$ & $\mathrm{P}<0.05$ & $\mathrm{P}<0.05$ & $\mathrm{P}<0.05$ & $\mathrm{P}<0.05$ & NS & $\mathrm{P}<0.05$ & $\mathrm{P}<0.05$ \\
\hline /ç/ & $\mathrm{P}<0.05$ & NS & NS & $\mathrm{P}<0.05$ & NS & $\mathrm{P}<0.05$ & $\mathrm{P}<0.05$ \\
\hline$/ \mathrm{c} /$ & NS & NS & NS & $\mathrm{P}<0.05$ & NS & $\mathrm{P}<0.05$ & $\mathrm{P}<0.05$ \\
\hline$/ \mathrm{j} /$ & $\mathrm{P}<0.05$ & $\mathrm{P}<0.05$ & NS & $\mathrm{P}<0.05$ & NS & NS & $\mathrm{P}<0.05$ \\
\hline$/ \mathrm{h} /$ & NS & NS & NS & $\mathrm{P}<0.05$ & NS & NS & $\mathrm{P}<0.05$ \\
\hline$/ \mathrm{y} /$ & NS & NS & NS & $\mathrm{P}<0.05$ & NS & NS & $\mathrm{P}<0.05$ \\
\hline
\end{tabular}

NS $=$ not statistically significant 
results revealed that disarticulation is observed in /s,sh/ phonemes when the vertical dimension is increased. These fricative phonemes are closely dependent on intraoral articulatory formations. Also, as a plosive phoneme, $/ \mathrm{t} /$ is found to be distorted when the vertical dimension of occlusion is increased. This articulation problem showed variations at frequencies according to the location of the phoneme at the beginning, middle or end of the word. In this study, the phonemes were widely affected from the first insertion of the prosthesis and most of them showed remarkable improvements after one week of use. When no improvements were observed in articulation of certain phonemes, alterations in prosthetic design was considered in parts of the prosthetic appliance that were thought to have caused the distortion in that phoneme.
After the insertion of the prosthesis, several problems occurred in addition to disarticulation, as previously reported by other researchers $(1,11)$. The amelioration in speech criteria was considered to be based on two important factors: received by the teeth and the adaptive capacity of the patient $(11,15)$. However, in total edentulousness, the problem is not only based on radical changes in the oral cavity, but also on the total loss of the source of proprioceptive inputs. The adaptation of patients with total edentulousness to new complete dentures implies the importance of the adaptive experiences of the patient in this process.

Chierchi et al. (16) reported that when passing from partial edentulousness to total edentulousness and the insertion of a new denture, the tactile and proprioceptive knowledge perceptions of temporomandibular

Table 2. McNemar test for detecting the differences between recording sequences, for those phoneme and criteria groups that had been found to have significant differences by the Cochrane Q test.

\begin{tabular}{|c|c|c|c|c|c|c|c|}
\hline Phonemes tested & Distortion & Omission & Substitution & Hypernasality & Hyponasality & Flow & Mass effect \\
\hline \multicolumn{8}{|l|}{ Anterior lingual } \\
\hline$/ \mathrm{t} /$ & $1-2$ & & & $1-3,1-2$ & & $2-3$ & $1-2,2-3$ \\
\hline$/ \mathrm{d} /$ & $1-3$ & & & $1-3,1-2$ & & $2-3$ & $1-2,2-3$ \\
\hline$/ \mathrm{n} /$ & $1-3$ & & & $1-3,1-2$ & & $2-3$ & $1-2,2-3$ \\
\hline$/ \mathrm{r} /$ & $1-2$ & $1-3$ & $1-3,2-3$ & $1-3,1-2$ & & $2-3$ & $1-2,2-3$ \\
\hline \multicolumn{8}{|l|}{ Posterior lingual } \\
\hline$/ \mathrm{k} /$ & & & $1-2,2-3$ & $1-3,1-2$ & & & $1-2,2-3$ \\
\hline /g/ & $1-2$ & & & $1-3,1-2$ & & & $1-2,2-3$ \\
\hline$/ \mathrm{b} /$ & $1-2,1-3$ & & & $1-3,1-2$ & & & $1-2,2-3$ \\
\hline \multicolumn{8}{|l|}{ Bilabial } \\
\hline$/ \mathrm{p} /$ & $1-2,1-3$ & & $1-3$ & $1-3,1-2$ & & & $1-2,2-3$ \\
\hline$/ \mathrm{m} /$ & & & & $1-3,1-2$ & & & $1-2,2-3$ \\
\hline \multicolumn{8}{|c|}{ Fricative and others } \\
\hline /s/ & & $1-3$ & $1-2,1-3,2-3$ & $1-3,1-2$ & & & $1-2,2-3$ \\
\hline $\mid \mathrm{z} /$ & & $1-3$ & $1-2,1-3,2-3$ & $1-3,1-2$ & & & $1-2,2-3$ \\
\hline$\tilde{O}$ & $1-3$ & & $1-2,1-3,2-3$ & $1-3,1-2$ & & & $1-2,2-3$ \\
\hline$/ \mathrm{f} /$ & $1-2$ & $1-3$ & $1-2,1-3,2-3$ & $1-3,1-2$ & & & $1-2,2-3$ \\
\hline$/ \mathrm{v} /$ & $1-3$ & & $1-2,1-3,2-3$ & $1-3,1-2$ & & & $1-2,2-3$ \\
\hline /ç/ & $1-3$ & $1-3$ & $1-2,1-3,2-3$ & $1-3,1-2$ & & & $1-2,2-3$ \\
\hline /c/ & & & $1-2,1-3,2-3$ & $1-3,1-2$ & & & $1-2,2-3$ \\
\hline$/ \mathrm{j} /$ & $1-3$ & $1-3$ & $1-2,1-3,2-3$ & $1-3,1-2$ & & & $1-2,2-3$ \\
\hline$/ \mathrm{h} /$ & & & $1-2,1-3,2-3$ & $1-3,1-2$ & & & $1-2,2-3$ \\
\hline$/ \mathrm{y} /$ & & & $1-2,1-3,2-3$ & $1-3,1-2,1-2$ & & & $1-2,2-3$ \\
\hline
\end{tabular}

1: The record before the insertion of the new prosthesis.

2: The record just after the insertion of the new prosthesis.

3: The record at the seventh day after the insertion of the new prosthesis. 
joints remain remembered and the articulation capability of the remaining articulatory organs remain unchanged.

Martone and Black (17) believe that speech is a learned, habitual neuromusculatory pattern and that after the loss of teeth and other oral tissues, in order to obtain comprehensive speech after variations in the oral structures, the formation of new neuromuscular patterns are necessary. Consequently, the clinician should not expect the patient to adapt to the new denture and establish new articulatory patterns for the oral tissues, but an effort should be made to determine the existing neuromuscular patterns and attempt to fabricate dentures accordingly.

Adaptation is easier in younger patients, and in older patients degenerative changes in auditory abilities make it difficult to adapt to new dentures, because speech is a learned process.

The results of this study revealed a significant decrease in articulatory problems of phonemes over time. However, Palmer (18) stated that speech problems after the insertion of new dentures are mostly dependent on how the patient was affected by this variation, and while some patients were significantly affected by minute variations, others understood the alterations in their speech only after environmental reactions, implying the importance of subjectivity in speech problems. The presence of speech problems, the understanding of these problems by the patient and how he/she would be affected should be determined before the fabrication of a new denture. The possible problems with a new denture and their solutions must be explained and, if necessary, cooperation with a speech pathologist must be recommended.

Seifert et al. (12) reported that although the thickness of the palatal plate is not a factor causing statistically significant differences, it could change the personal sound spectrum and range. Özkan et al. (9) reported that patients in whom orthodontic appliances with 2-3-mm thick palatal plate were inserted could adapt to articulation of tip of tongue and rear tongue phonemes within one week. Their slightly better adaptation observations compared to this study may be due to their younger patient population. Hamlet and Stone (19) reported that 6 of 13 patients exhibited lisping after the insertion of the denture and they noted the frequent tongue movements in anteroposterior directions in order to compensate lisping. In previous studies with young adult patients, the same researchers reported that most of the test subjects adapted to a palatal plate in a few days to a few weeks, and noted that in most cases with childhood lisping, the speech problems may be lost in adulthood but whatever speech defect was encountered in childhood may lead to higher than normal defects in speech adaptation as age increases.

The principal factors of amelioration of articulation problems of patients with removable partial dentures are the proprioceptive sensor inputs and their adaptive properties. Adaptation to dentures improves over time and the articulation defects decrease by the 3rd day and become minimal by the 7th day.

Proprioceptive sensor inputs and adaptive properties not only assist to improve articulation, but also help to decrease other problems caused by removable partial dentures.

\section{RESUMO}

Nesse estudo a adaptação dos pacientes ao uso de próteses parciais removíveis foi avaliada quando relacionada a pronunciação de fonemas turcos. A pronunciação dos fonemas / t,d,n,l,r/,/g,k/,/b,p,m/e /s,z, Õ,v,f,y,j,h,c/ foram avaliadas por três fonoaudiologos, em avaliações tomadas em indivíduos antes da inserção da prótese parcial removível, logo após sua inserção, e uma semana após. O teste constituía-se da avaliação da pronunciação de fonemas em sílabas independentes quanto a sua distorção, omissão, substituição, mass effect, hiper ou hipoanasalação. A análise estatística foi realizada com os testes de Cochrane Q, McNemar e Kruskal-Wallis. Os resultados evidenciaram que alguns fonemas apresentavam problemas com a pronunciação após a inserção da prótese parcial removível, em outras havia uma melhora. Em geral, os problemas originados da pronunciação dos fonemas avaliados pela inserção da prótese parcial removível foram resolvidos em uma semana de uso.

\section{REFERENCES}

1. Dinçer C. Evaluation of phonemic articulation in complete denture wearers G. Ü. DiÕhek Fak Dergisi 1999;16:29-35.

2. Kent K, Schaaf NG. The effects of dental abnormalities on speech production. Quintessence Int 1982;12:1353-1363.

3. Rothmann R. Phonetic considerations in denture prosthesis. J Prosthet Dent 1961;2:214-223.

4. McCord JF, Firestone HJ, Grant AA. Phonetic determinants of tooth placement in complete dentures. Quintessence Int 1994;25:341-345.

5. Lundqvist S, Karlsson S, Lindblad P, Rehnberg I. An electropalatographic and optoelectronic analysis of Swedish [s] production. Acta Odontol Scand 1995;53:372-380.

6. Faulmann C. Das Buch der Schrift enthaltend die Schriftzeichen und Alphabete aller Zeiten und aller Völken des Erdcreises, 1878, (Translation in Turkish), Türkiye IÕ Bankasi Kültür Yayinlari, Mas A.Ô., Istanbul; 2001. 
7. Kawauchi M, Kawamori Y, Sachdeva R, Nakajima H, Mitani H The dynamic dento-palatography system: A new approach for evaluating speech. J Biomed Eng 1992;14:163-168.

8. Glass I, Knapp J, Bloomer HH. Speech and lingual behavior before and after mandibular osteotomy. J Oral Surg 1977;35:104109.

9. Özkan S, Haydar B, Karabulut G, Aksoy A, Ci-er S. Effects of retainers on articulation of speech. $70^{\text {th }}$ Congress of European Orthodontic Society, Graz, Austria, June 8-11, 1994.

10. Bowers J, Toby EA, Shaye R. An acoustic speech study of patients who received orthognathic surgery. Am J Ortho 1985;88:373-379.

11. Horn H, Götz G, Bacher M, Müllauer M, Kretschner I, AxmannKromer D. Reliability of electromagnetic articulography recording during speaking sequences. European J Orthod 1997;19:647665 .

12. Seifert E, Runte C, Riebandt M, Lamprecht-Dinnesen A, Bollmann F. Can dental prostheses influence vocal parameters? J Prosthet Dent 1999;81:579-585.
13. Saunders TR, Oliver NA. A speech-aid prosthesis for anterior maxillary implant supported prostheses. J Prosthet Dent 1993;70:546-547.

14. Hammond R, Beder OE. Increased vertical dimension and speech articulation errors. J Prosthet Dent 1984;52:401-406.

15. Pound E. Controlling anomalies of vertical dimension and speech. J Prosthet Dent 1976;36:124-135.

16. Chierchi G, Parker ML, Hemphill CD. Influence of immediate replacement dentures on oral motor skill and speech. J Prosthet Dent 1978;39:21-27.

17. Martone AL, Black JW. The phenomenon of function in complete denture prosthetics: Speech science research of prosthodontic significance. J Prosthet Dent 1962;12:629-635.

18. Palmer JM. Structural changes for speech improvement in complete upper denture fabrication. J Prosthet Dent 1979;41:507510.

19. Hamlet SL, Stone M. Speech adaptation to dental prostheses. The former lisper. J Prosthet Dent 1982;47:564-569.

Accepted September 30, 2002 